Kalpa Publications in Engineering
Volume 3, 2020, Pages 123-132
Proceedings of International Sym-
posium on Applied Science 2019

\title{
On The Aerodynamic Interactions Analysis Between The Main Rotor And The Helicopter Fuselage
}

\author{
Thanh Dong Pham ${ }^{1}$, Anh Tuan Nguyen ${ }^{1}$, Ngoc Thanh Dang ${ }^{1}$, Vu Uy Pham ${ }^{1}$ \\ ${ }^{1}$ Le Quy Don Technical University, Hanoi, Vietnam \\ mrbook29@gmail.com
}

\begin{abstract}
This paper develops a numerical method that is capable of analyzing the aerodynamic characteristic of the helicopter main rotor in consider influence of fuselage. The method is based on an unsteady nonlinear vortex-lattice method that can be used to simulate the interactions among the helicopter components efficiently. To clarify the effect of the main rotor-fuselage interaction, the aerodynamic characteristics of the main rotor in consider the influence of fuselage is determined along with those of the combined main rotor-fuselage system. The paper also shows the velocity field and free wake model in several flight regimes. The fuselage is modelled as a streamlined object, which is discretized into the system of quadrilateral vortex panels. The nopenetration boundary condition is satisfied on the fuselage surface, and no vorticity is shed from the fuselage. The results obtained in this paper are validated against experimental data and some from previous numerical methods.
\end{abstract}

\section{Introduction}

A helicopter main rotor or rotor system is the combination of several rotary wings (rotor blades) and a control system that generates the aerodynamic lift force to support the weight of the helicopter, and the thrust that counteracts aerodynamic drag in forward flight. Thus far, there has been a great deal of studies on helicopters, especially on the aerodynamics of helicopter main rotor. However, research on the aerodynamic interaction between helicopter components, such as main rotor, fuselage, tail rotor, and stabilizers, is still quite limited. Main rotor is mounted on a vertical mast over the top of the helicopter, andthe aerodynamic characteristics of a helicopter main rotor itself can be determined by various different numerical methods $[1,2,3,4,5,6,7]$. Nevertheless, these characteristics may be altered when the aerodynamics of the fuselage is taken into consideration. The questions of how the main rotor-fuselage aerodynamic interaction takes place and to what degree this interaction affects the performance of a helicopter have not been answered entirely. In fact, the fuselage can obstruct the 
induced downward flow generated by the main rotor; thus, the effective disk area of the main rotor is reduced and the lift force decreases. On the other hand, the fuselage can play a role of an undersurface that can enhance the aerodynamic performance of the main rotor in a similar way to the ground effect.

Recently, with the development of computational techniques, the use of high-performance computers, a number of studies on multifarious systems have been studied. Works of Игнаткин Ю.М [3] on the interaction between the main rotor and tail rotor of helicopter used a discrete vortex method. However, due to the complexity of the multi-component aerodynamics system the results of the works are often not verified or compared to other calculations.In the work [8], Tan Jianfengand Wang Haowen used the unsteady potential-based panel method to consider aerodynamics of finite thickness multi-bladed rotors, and the full-span free-wake method is applied to simulating dynamics of rotor wake. These methods are tightly coupled through trailing-edge Kutta condition and by converting doublet-wake panels to full-span vortex filaments. A velocity-field integration technique is also adopted to overcome singularity problem during the interaction between the rotor wake and blades. By method as CFD-FASTRAN solver, Sijun Zhang, MadhaveswerGentela and T. Fuchiwaki [15] realized the computational simulation of flows over the generic rotor body interaction (ROBIN) configuration. The helicopter model studied in this work consists of a fuselage, a four-bladed rotor, and tails. The results of this work show that low Mach number preconditioning and dual timestepping greatly improve the accuracy and efficiency of CFD-FASTRAN for helicopter flows. But in this work is not shown the influence of the body (fuselage) on the aerodynamic characteristics of the main rotor. In the studies of XU HeYong and Bum Seok Lee and colleagues [16, 17] used the CFD method on the basis of unstructured meshing to simulate the aerodynamic characteristics of the rotary wing with body of helicopter. Both of these works focused on calculating the pressure distribution on the helicopter body in case the helicopter moves alone in space or when the helicopter body moves in the air from the rotating wing. The influence of the body on the aerodynamic properties of the rotary wing was not studied.

For the purpose of creating a rotary wing air computational tool that overcomes the limitations mentioned above, simulating and investigating many cases (taking into account compressibility, viscosity of the environment, considering the influence the helicopter fuselage or other parts), the authors have studied the model, describing aerodynamic interaction between helicopter main rotor blades and its fuselage by the discrete method as follows.

\section{Formulation Theory For Analyzing Of Aerodynamic Interactions}

The mathematical model of helicopter main rotor has been developed,whichis based on an unsteady nonlinear vortex-lattice method (UVLM) $[10,14,18,19]$.This method assumes that an inviscid, irrotational, and incompressible flow around the body.Therefore, it does not take into account viscous effects, flow separation at the leading edge, and compressibility at high Mach numbers. In UVLM, lifting surfaces and wakes are discretized by using so-called vortex rings, quadrilateral elements composed by discrete vortex segments in a closed loop. The wake vortex-rings are freely convected according to the local flow velocity, developing into a force-free wake.

It is clearly that the construction of the vortex model must be based on the boundary condition of the infiltration such as the impermeability condition on lifting surfaces, Traplugin-Zoukovsky condition for the finite velocity at the edges of the load surface (Kutta condition), Kelvin condition of vortex intensity in closed loop [1,9]. For a single vortex model of main rotor, blades were replaced by vortex surface with vortex ring elements. The main advantage of using vortex ring elements is that they require little programming effort (although computational efficiency can be further improved). 
All the rules of vortex theory alluding to the set-up problem and solving the linear equation to determine the circulation of each vortex ring component. The linear equation system contains vortex circulation variables for a main rotor in the general form as follows $[1,3,9]$ :

$$
\left(\begin{array}{cccc}
a_{11} & a_{12} & \cdots & a_{1 m} \\
a_{21} & a_{22} & \cdots & a_{2 m} \\
\vdots & \vdots & \ddots & \vdots \\
a_{m 1} & a_{m 2} & \cdots & a_{m m}
\end{array}\right) \cdot\left(\begin{array}{c}
\Gamma_{1} \\
\Gamma_{2} \\
\vdots \\
\Gamma_{m}
\end{array}\right)=\left(\begin{array}{c}
R H S_{1} \\
R H S_{2} \\
\vdots \\
R H S_{m}
\end{array}\right)
$$

In this case, the right-hand side of the Eq. (1) is the sum of the free stream velocity, rotation velocity, and the velocity induced by the free wake at each control point on blades of main rotor. It is defined as $R S H_{k}=-\left[U(t)+u_{w}, V(t)+v_{w}, W(t)+w_{w}\right]_{k} \cdot n_{k}, k=1 \div m$; where - is number of vortices replacing on blades, $m=n . N . s l c, n$ - is number of vortices divided on blade in the chordwise direction; $N$ - number of vortices divided on blade in the spanwise direction, slc- number of blades on main rotor. The coefficients $a_{i j}$ are determined by the Bio-Savar law for each quadrilateral vortex on blades of main rotor [1, 4], where $i=1 \div n, j=1 \div N ; \Gamma_{k}$ - is the circulation of the associated vortices on the main rotor.

\subsection{Unsteady Kutta Condition}

The Kutta condition states that the flow leaves tangentially the trailing edge of blades. That is, velocity at the trailing edge is finite. The unsteady Kutta condition is imposed in UVLM by shedding the vorticity generated along a sharp trailing edge into the wake $[1,4]$. This condition forces the pressure jump across the trailing edge to be zero, allowing the fluid to leave the surface smoothly. The nodes on the wake are allowed to move freely with local fluid particle speed, rendering the wake force-free.The solution is based on the time-stepping technique, and at the beginning of the motion only the main rotor-bound vortex rings exist. Note that the closing segment of the trailing-edge vortex elements will represent the starting vortex. During the second time step, the main rotor is moved along its flight path and each trailing-edge vortex panel sheds a wake panel with a vortex strength, which equals to its circulation in the previous time step [9].

$$
\Gamma_{\mathrm{W}_{t}}=\Gamma_{\mathrm{T}_{\mathrm{E}}-\Delta t}
$$

Here $\Gamma_{\mathrm{w}_{t}}$ is strength of wake vortex at time step $\mathrm{t}$, and $\Gamma_{\mathrm{T} \cdot \mathrm{E}_{t-\Delta t}}$ is strength of bound vortex at trailing-edge of main rotor blades at previous time step t-1. This time-stepping methodology can then be continued for any type of flight path and at each time step, the wake vortex corner points can be moved by the local velocity, so that wake rollup can be simulated (Eq. (8).

\subsection{Treatment of Core Radius}

The core radius of the vortex ring plays an important role in evaluating induced velocities, especially when calculating self-induced velocities. Therefore, it is necessary to model the development of the core radius over time. Viscous diffusion leads to an expansion of the vortex core and a decrease in the maximum magnitude of vortex swirl velocity with time. Consequently, the volume of the toroidal vortex is no longer conserved. However, total circulation and angular momentum are conserved. If the vortex wake structure is considered to be highly turbulent, a simple laminar viscosity model (for example, Lamb Oseen's) would prove insufficient. Therefore, following the approach of Squire, Bhagwat and Leishman [11,12], the core radius growth is approximated by

$$
r_{c}=\sqrt{r_{0}^{2}+4 \cdot \alpha_{L} \cdot v \cdot \delta \cdot t}
$$


Where $\delta$ the viscosity parameter is representative of the turbulent viscosity in the medium and it is empirically obtained, $\alpha_{L}=1.25643$ is Lamb's constant, is the coefficient of viscosity, and t is the time elapsed since the formation of the tip vortex. Note that $\delta$ depends on the vortex Reynolds number, which is obtained from measurements on our experimental setup. Here establishing an initial core radius, $\mathrm{r}_{0}$ at 0 degree of vortex age.

In this model, the 3D body of the helicopter fuselage is a closed volume, the hull surface is replaced by quadrilateral vortex ring elements. At each control point on the surface of helicopter fuselage simultaneously satisfies the impermeability condition as applied on the surfaces of the rotating blades in the same time step. The fuselage is considered a 3D-shaped object, which has an induction effect on the performance of helicopter main rotor and there is no free wake formation when the air flows through the helicopter fuselage. In this work, 540 vortex ring elements are considered, the helicopter fuselage is positioned below the main rotor as shown in Figure 1. The distance from 3D body of the helicopter fuselage to the rotational plane of main rotor is $h$.

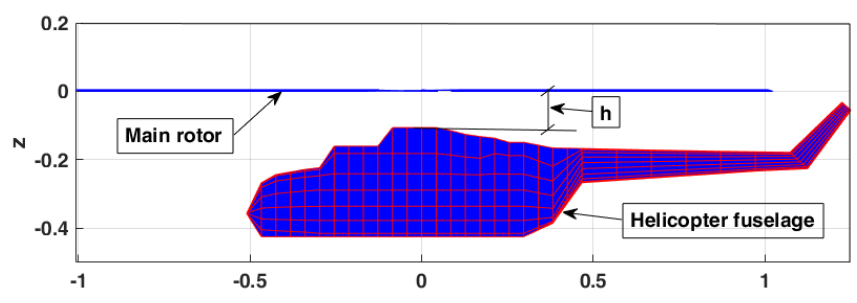

Figure 1. Main rotor- fuselage model

Then the linear system of equations determining the circulations of the vortices in the multicomponents system helicopter main rotor- fuselage will be greatly expanded as follows:

$$
\left[\begin{array}{cc}
\left(A 1_{m \times m}\right) & \left(A 2_{m \times M}\right) \\
\left(A 3_{M \times m}\right) & \left(A 4_{M \times M}\right)
\end{array}\right]\left[\begin{array}{c}
\left(\Gamma_{m \times 1}\right) \\
\left(\Gamma_{M \times 1}^{T h}\right)
\end{array}\right]=\left[\begin{array}{c}
\left(R H S_{m \times 1}\right) \\
\left(B 2_{M \times 1}\right)
\end{array}\right]
$$

Here in Eq. (4), the matrices of coefficients A2, A3, A4, and B2 are defined by the vortex elements on helicopter fuselage (quadrilateral vortex panels). Particularly A2 is the coefficient matrix generated by vortex bounds on helicopter calculated at the control points on main rotor. A3 is the matrix of coefficients of vortex elements on the main rotor calculated at the control points on helicopter fuselage. A4 is the coefficient matrix of the vortex bounds on helicopter fuselage at its control points. $\Gamma^{T h}$ is the circulation matrix of the vortices on the helicopter fuselage, and B2 is the matrix of the coefficients determined by the normal components of the no-noise constant velocity with the velocity of the induced vortex at the control points on the fuselage. With $\mathrm{M}$ is the total number of vortices generating the 3D model of the helicopter fuselage, $M=$ sgnxsgd, in which sgn, sgd are the number vortex on horizontal and vertical directions of the 3D model.

Comparing Eqs. (1) and (4), it is found that when considering the influence of the helicopter fuselage on the performance of the main rotor, the linear system of determining the vortex circulations has expanded considerably. This means that the calculated time-wasting in the multicomponent system also increases several times.

\subsection{Aerodynamic Forces and Moments}

Determination strength values of vortices on main rotor-fuselage is the basis for analyzing the aerodynamic characteristics of the model, such as the differential pressure, lift, drag, moment coefficients, and velocity fields. The local circulation is needed in calculating the pressure distribution. For the leading-edge panel, strength of this is equal to $\Gamma_{i, j}$ but for all the elements 
behind it, the strength of vortex panel is equal to the difference $\Gamma_{i, j}-\Gamma_{i-1, j}$. The fluid dynamic loads then can be computed by using the Bernoulli equation, and the pressure difference is given by Eq. (5) $[1,9]$.

$$
\begin{aligned}
\Delta p_{i j} & =\rho\left\{\left[\mathrm{U}(\mathrm{t})+\mathrm{u}_{\mathrm{w}}, \mathrm{V}(\mathrm{t})+\mathrm{v}_{\mathrm{w}}, \mathrm{W}(\mathrm{t})+\mathrm{w}_{\mathrm{w}}\right]_{\mathrm{ij}} \cdot \tau_{i} \frac{\Gamma_{i, j}-\Gamma_{i-1, j}}{\Delta c_{\mathrm{ij}}}\right. \\
& \left.+\left[\mathrm{U}(\mathrm{t})+\mathrm{u}_{\mathrm{w}}, \mathrm{V}(\mathrm{t})+\mathrm{v}_{\mathrm{w}}, \mathrm{W}(\mathrm{t})+\mathrm{w}_{\mathrm{w}}\right]_{\mathrm{ij}} \cdot \tau_{j} \frac{\Gamma_{i, j}-\Gamma_{i, j-1}}{\Delta b_{\mathrm{ij}}}+\frac{\partial}{\partial t} \Gamma_{\mathrm{ij}}\right\}
\end{aligned}
$$

Here $\tau_{i}, \tau_{j}$-are the panel tangential vectors in the $\mathrm{i}$ and $\mathrm{j}$ directions; $\Delta c_{\mathrm{ij}}, \Delta b_{\mathrm{ij}}$-are the panel lengths in the $\mathrm{i}$-th and $\mathrm{j}$-th directions. The time derivative of the velocity-potential is obtained by using the definition $\frac{\partial}{\partial t} \Phi_{\mathrm{ij}}=\frac{\partial}{\partial t} \Gamma_{\mathrm{ij}}=\frac{\Gamma_{\mathrm{ij}}{ }^{t}-\Gamma_{\mathrm{ij}}{ }^{t-\Delta t}}{\Delta t}$. The pressure distribution is numerically integrated along the surface to yield the acting force $\left(\mathrm{C}_{\mathrm{f}}\right)$ and moment $\left(\mathrm{C}_{\mathrm{m}}\right)$ coefficients.

$$
\begin{gathered}
C_{f}=-\sum_{k}^{m}(\Delta p \cdot \Delta S)_{k} \cdot \mathbf{n}_{k} \\
C_{m}=-\sum_{k}^{m}(\Delta p \cdot \Delta S \cdot r)_{k} \cdot \mathbf{n}_{k}
\end{gathered}
$$

\section{Validation And Discussions}

\subsection{Validation model of single main rotor with model of Б.С. Крицкий [13]}

In the rotor model of Б.С. Крицкий [13], dimensions of rotor blade are $b \times R=0.15 \times 1.2$, pitch angle is $8^{0}$, rotational speed $\omega=36.5 \mathrm{rad} / \mathrm{s}$. When rotor velocity is $Q_{\infty}=11.5 \mathrm{~m} / \mathrm{s}$, we get vortex structure in work of Б.С. Крицкий [13] and this work at azimuth $180^{\circ}$ and $270^{\circ}$ as shown in Figure 2, and get values of coefficients of normal force plotted in Figure 3. From Figures 2 and 3, we can found that this work and Б.С. Крицкий's [13] are in good agreement.

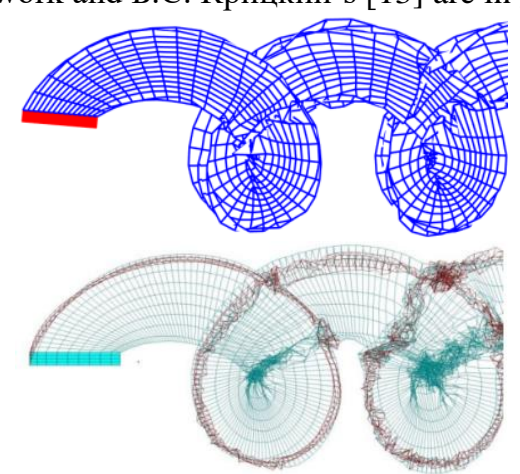

Azimuth $180^{\circ}$ : Top -this work; Bottom - Б.С. Крицкий [13]

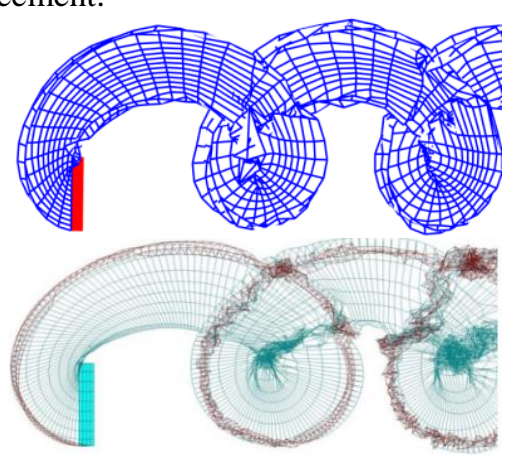

Azimuth $270^{\circ}$ : Top - this work; Bottom - Б.С. Крицкий [13]

Figure 2. Comparing of vortex structure 

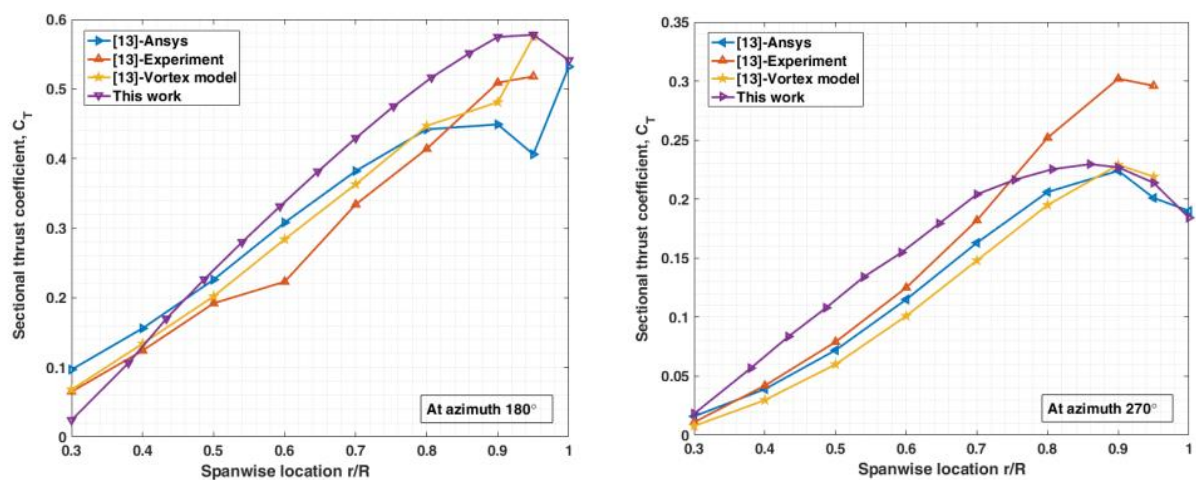

Figure 3. Coefficients of normal force for the length of rotor blade

\subsection{Validation model of single main rotor with model of Juan D. Colmenares [14]}

In the study of Juan D. Colmenares [14], helicopter rotor in hover flight, the rotor with two untapered and untwisted rectangular blades of aspect ratio AR $=6$ is modelled. The blades were confgured at a collective pitch of $5^{0}, 8^{0}$, and $12^{0}$. Speed rotating of rotor is $1250 \mathrm{RPM}$, which corresponds to a tip Mach number of 0.439. Using the mathematical model of the author with the above geometric parameters, we obtain the results plotted in Figures 4 and 5.

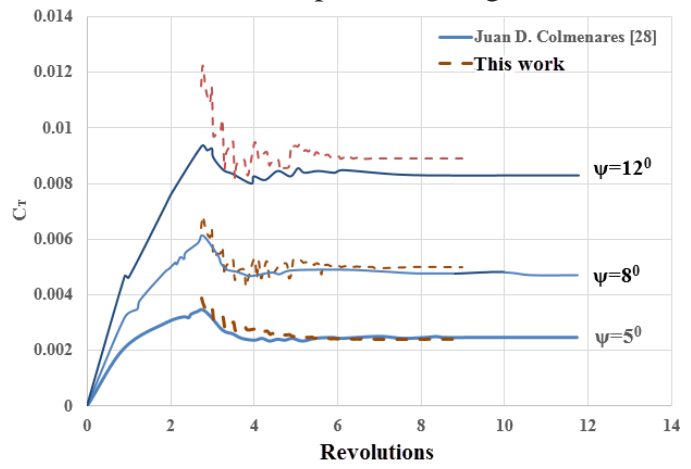

Figure 4. Thrust coefficient of the rotor at different collective pitch angles

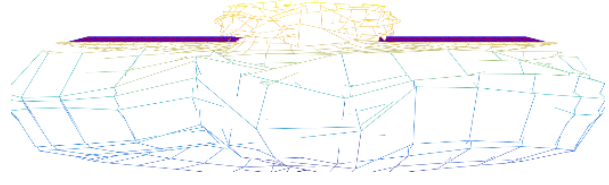

a) This work, at 3 revolutions

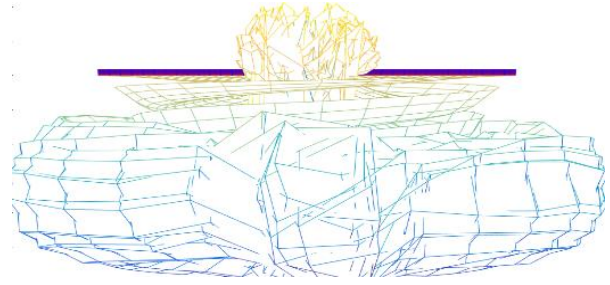

c) This work, at 6 revolutions

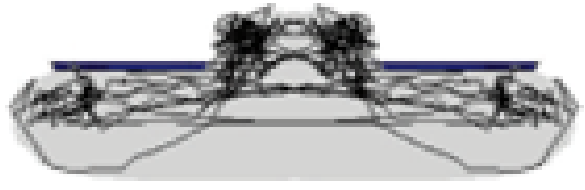

b) Juan D. Colmenares [14], at 3 revolutions

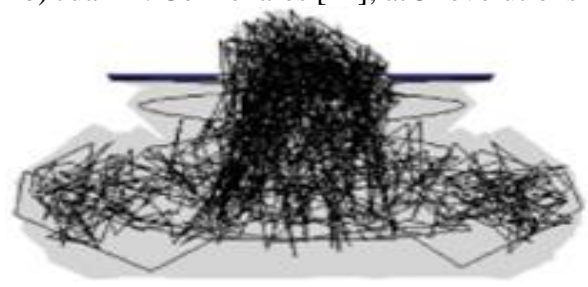

d) Juan D. Colmenares [14], at 6 revolutions

Figure 5. Wake structure for the case collective pitch angle is $12^{0}$ 
Result of thrust coefficient on this rotor model, converging to an average value similar to that achieved with the model of Juan D. Colmenares [14], we can see clearly this in Figure 4. A comparison of the two wake structures is shown in Figure 5, it is also clear that this work and the results in [14] are similar. The figure 5 shows that the helix after the helicopter also tends to roll, forming the stretched tube vortex and move turbulence in the space, similar to trace vortex of wing.

\subsection{Calculating results with model main rotor- fuselage}

Based on the proposed model for main rotor- fuselage system, we continue to apply on the specific calculation conditions. Dimensions of main rotor blade in this model are $b \times R=0.52 \times 10.2 \mathrm{~m}$, in which $\mathrm{b}$ is chord width and $\mathrm{R}$ is span width of blade, the radius rotate axle of blade: $\mathrm{R}_{\mathrm{tr}}=0.25 \mathrm{R}$. Rotational speed of revolving $\omega=20.1 \mathrm{rad} / \mathrm{s}$; initial pitch angle $\varphi=12^{0}$; main rotor rotates counterclockwise (viewed from top view); number of rotor blades, sl=2; time step $\Delta t=0.01 \mathrm{~s}$.

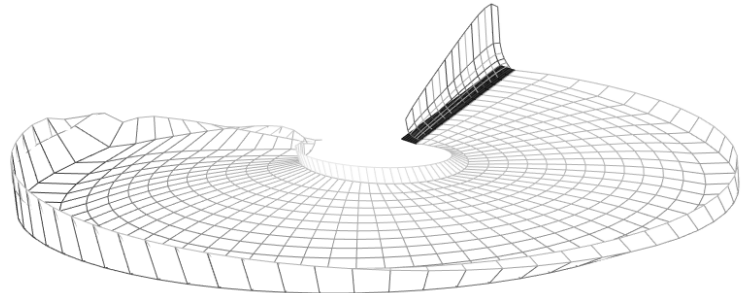

Figure 6. The distribution of vortex strengths on blade at 50th time step

Figure 6 shows computed results with main rotor, which has one blade at the 50th time step. The distribution of vortex strengths on blade obtained is increasing by spanwise and decreasing by chordwise of blade. This result is consistent with the theory of helicopter aerodynamics.
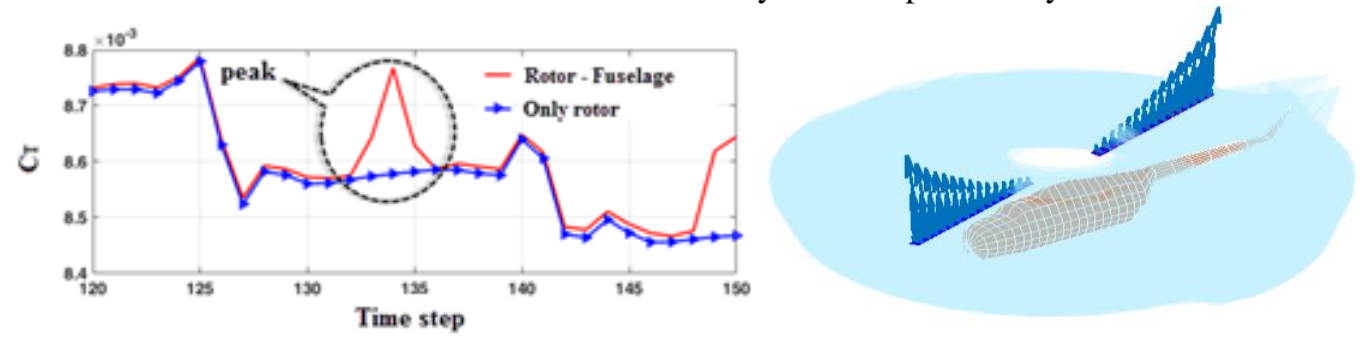

Figure 7. The transient lift coefficient of rotor and the root wake of in hover

Comparison of simulation results from the helicopter main rotor model with and without fuselage in different regime flight is shown in Figures 7, 8 and 9. In these figures, main rotor model and main rotor-fuselage model are computed in the hover processing. After 150 time steps, the airflow through the rotating main rotor was pushed downward and obtained an image of vortex wake in the vertical plane through the center of rotation as shown in Figure 7. The root vortex effect can be observed clearly on that plane, too. The variation of the lift coefficient of the main rotor in the two models is beginning to converge. The average difference between the values of lift coefficient in main rotor model and in main rotor-fuselage model model is not significant, the lift coefficient in the rotorfuselage model is greater than the lift coefficient in the only rotor model, about 5\%. In Figure 8, the helicopter moves up vertical with velocity $10 \mathrm{~m} / \mathrm{s}$, the lift coefficient has a larger mean value than that in the hover processing, and the dynamic variation is stronger over time, which is consistent with many other studies. The transient lift coefficient of rotor when helicopter vertical descent with velocity $\mathrm{v}_{\mathrm{z}}=-10 \mathrm{~m} / \mathrm{s}$ is shown in figure 9 . The forward flight with a speed of $\mathrm{U} 0=50 \mathrm{~m} / \mathrm{s}$, angle of attack $\pm 10^{\circ}$, the free wake vortex of main rotor-fuselage model is simulated and shown in Figures 10 . 


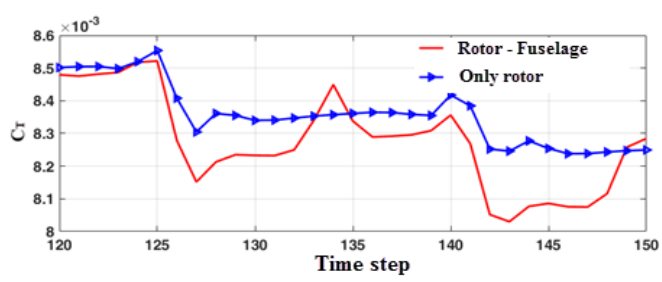

Figure 8. The transient lift coefficient of rotor when helicopter vertical climbing with $\mathrm{v}_{\mathrm{z}}=10 \mathrm{~m} / \mathrm{s}$

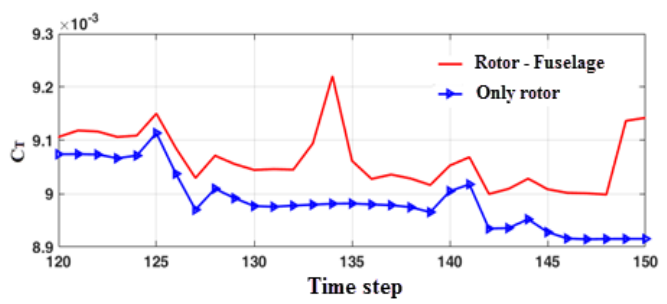

Figure 9. The transient lift coefficient of rotor when helicopter vertical descent with $\mathrm{v}_{\mathrm{z}}=-10 \mathrm{~m} / \mathrm{s}$

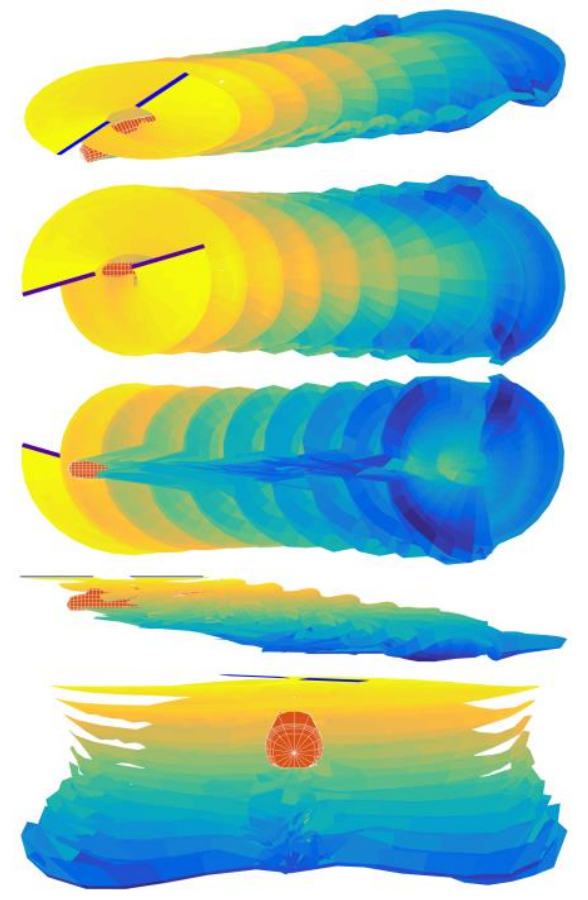

Figure 10. The vortex wake when helicopter in forward flight

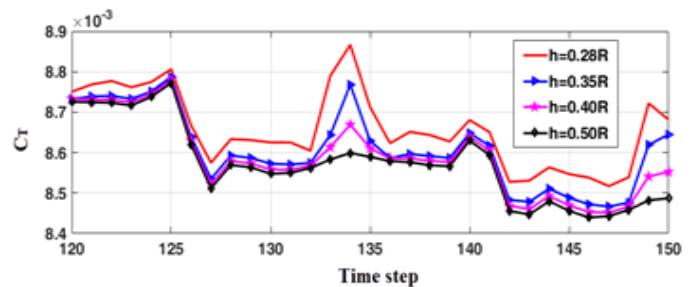

Figure 11. The transient lift coefficient of rotor at various distances of $h$
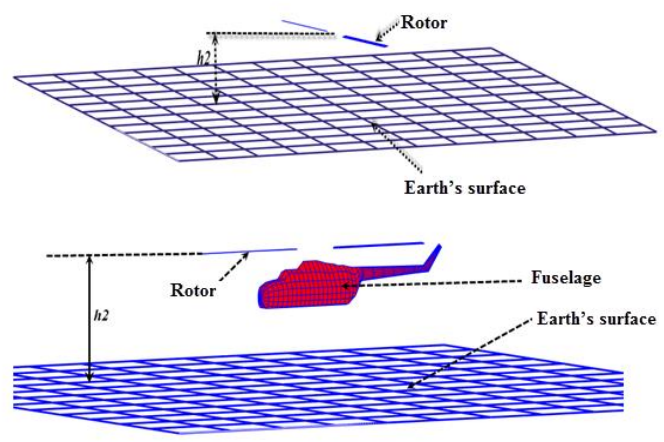

Figure 12. The model of helicopter working in ground

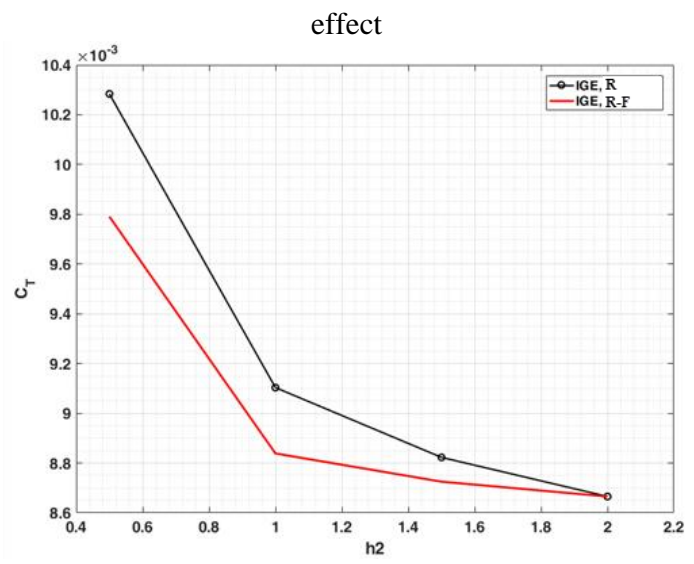

Figure 13. The comparesion of lift coefficient when helicopter in ground effect

Figures 11 show the results of the relative position survey between the main rotor and the helicopter fuselage. As shown in Figure 1, the helicopter fuselage is located underneath the rotor a distance of ( $\bar{h}=h / R$-non-dimensional quantities). With different types of helicopters depending on the structural characteristics that distance may be short or long. Here the distance is measured in the range of $0.28,0.35,0.4$, and 0.5 . The results show that the forming wake vortex characteristics and 
the variation of the rotor lift coefficient are not significantly different when changing the distance value. It can be seen that the selection of the appropriate distance between the main rotor and the helicopter fuselage depends more on the factorial structural strength of the rotary shaft than on the aerodynamic performances. Figure 12 shows models that describe helicopter working in ground effect. And the results when helicopter work in ground effect with various distances $h_{2}$ are shown in figure 13.

\section{Conclusions}

In the paper, the author has set up a mathematical model to study the aerodynamic characteristics of the main rotor in consider influence of helicopter fuselage by unsteady nonlinear vortex-lattice method. Computational simulation and comparison of individual main rotor model with the main rotor-fuselage model in multiple flight regimes. The results are consistent with the theory of helicopter aerodynamics.

In the model main rotor-fuselage, influence of helicopter fuselage on the aerodynamic characteristics of the main rotor in terms of lifting force is not large, only about $5 \div 7$ percent. Thus, in some preliminary calculations of flight regimes may bypass the presence of the fuselage to reduce the calculated volume. The dynamic load impacting on blades of main rotor in the model main rotorfuselage is very significant, especially in the skew flow regime, it is necessary to develop the model to continue the research.

\section{Acknowledgment}

This research is funded by Vietnam National Foundation for Science and Technology Development (NAFOSTED) under grant number 107.01-2018.05.

\section{References}

[1] Белоцерковский СМ, Локтев БЕ, Ништ МИ. Исследование на ЭВМ аэродинамических и аэроупругих характеристик винтов вертолётов:- М.: Машиностроение, 1992 - 219 с. - ISBN 5217-01368-0.

[2] Макеев ПВ, Шомов АИ. Численное моделирование режимов «вихревое кольцо» несущего винта вертолета. Электронный журнал «Труды МАИ», Выпуск № 45;

[3] Игнаткин ЮМ, Макеев ПВ, Шомов АИ. Численное исследование аэродинамической интерференции несущего и рулевого винтов вертолета на особых режимах полета. Научный вестник МГТУ ГА. 2014, 200, pp. 47-54.

[4] Артамонов БЛ. Расчет индуктивных скоростей несущего винта на основе модели с непрерывно распределенной циркуляцией вихревого слоя. Научный вестник МГТУ ГА. 2015, 211, pp.37-44.

[5] Шайдаков ВИ. Индуктивные Свойства Изогнутых Вихревых Шнуров И Их Приложение К Построению Модели Вихревого Следа Несущего Винта Вертолета. Научный вестник МГТУ ГА. 2016, 223, pp. 84-92.

[6] Лебедь ВГ, Калкаманов СА. Математическая модель нелинейной аэродинамики вертолета одновинтовой схемы для задач моделирования динамики полета на вертолетных тренажерах. Системи обробки информации 2015, випуск 7 (132), ISSN 1681-7710, УДК 629.735.45, стр 50-54. 
[7] Oleg S, Vitaliy K, Sergey Y. Mathematical Modeling of the Flow behind Propeller. Studies in Engineering and Technology 2015, 2 (1), pp. 77-85.

[8] Tan J, Wang H. Panel/full-span free-wake coupled method for unsteady aerodynamics of helicopter main rotor blade. Chinese Journal of Aeronautics 2013, 26(3), pp. 535-543.

[9] Katz J, Plotkin A. Low-speed aerodynamics: Cambridge University Press, 2001;

[10] Hankin D, Graham JMR. An unsteady vortex lattice method model of a horizontal axis wind turbine operating in anupstream rotor wake. The Science of Making Torque from Wind 2012. Journal of Physics: Conference Series 555, 2014, 012049.

[11] Squire HB. The growth of a vortex in turbulent flow. The Aeronautical Quarterly, 16, August 1965, pp. 302-306.

[12] Bhagwat MJ, Leishman JG. Generalized viscous vortex core models for application to freevortex wake and aeroacoustic calculations. American Helicopter Society 58th Annual Forum Proceedings, Montreal, Canada, June 11-13, 2002.

[13] Крицкий БС, Махнёв МС, Миргазов РМ, Субботина ПН, Требунских ТВ. Aerodynamic characteristics calculation on single rotor blade using FLOEFD, Ansys fluent and RC-VTOL. Civil Aviation High Technologies 2016, 223, pp. 77-83. (In Russian).

[14] Juan DC, Omar DL, Sergio P. Computational Study of a Transverse Rotor Aircraft in Hover Using the Unsteady Vortex Lattice Method. Hindawi Publishing Corporation Mathematical Problems in Engineering, 2015, Article ID 478457, pp. 1-9;

[15] Sijun Z, Madhaveswer G, Fuchiwaki T. CFD Developments for Unsteady Aerodynamics of Rotorcraft in Forward Flight with Realistic Motion Schedules. AIAA Computational Fluid Dynamics, 19th, 2009.

[16] Xu HY, Ye ZY. Numerical simulation of rotor-airframe aerodynamic interaction based on unstructured dynamic overset grids. SCIENCE CHINA- Technological Sciences 2012, 55(10), pp. 2798-2807;

[17] Bum SL, Mun SJ, Oh JK. Numerical Simulation of Rotor-Fuselage Aerodynamic Interaction Using an Unstructured Overset Mesh Technique. Int' 1 J. of Aeronautical \& Space Sciences 2010, 11(1), pp. 1-9.

[18] Mehdi G, Daniel G, Nathan C, Victor C. A Fast, Portable Computational Framework for Aerodynamic Simulations. World Academy of Science, Engineering and Technology International Journal of Aerospace and Mechanical Engineering 2018, 12(5), pp. 517-521. 